\title{
TENDÊNCIA DA MORTALIDADE POR ACIDENTES DE TRANSPORTE TERRESTRE EM IDOSOS NO BRASIL
}

\author{
Giovana Aparecida de Souza Scolari ${ }^{1}$, Flávia Maria Derhun ${ }^{1}$, Diogo Francisco Rossoni², Thais Aidar de \\ Freitas Mathias ${ }^{3}$, Carlos Alexandre Molena Fernandes ${ }^{4}$, Lígia Carreira ${ }^{5}$
}

\begin{abstract}
RESUMO: O objetivo foi analisar a tendência da mortalidade por acidentes de transporte terrestre em idosos brasileiros no período de 1996 a 2013. Estudo ecológico, de séries temporais com dados secundários captados pelo Sistema de Informação sobre Mortalidade, em abril de 2015, referentes aos óbitos por acidentes de transporte. Houve 88.273 óbitos por acidentes de transporte terrestre no período estudado entre idosos brasileiros. Todas as regiões apresentaram crescente tendência de mortalidade por acidentes de transporte, tendo o Nordeste a maior tendência, seguida do Sul, Norte, Sudeste e Centro-Oeste. Os resultados apontam a importância da vigilância de acidentes de transporte no apoio à implementação de políticas efetivas na promoção da saúde, prevenção e redução destes eventos.
\end{abstract}

DESCRITORES: Acidentes de trânsito; Mortalidade; Idoso; Estudos de Séries Temporais; Enfermagem Geriátrica.

\section{TREND IN MORTALITY OF ELDERLY BY LAND TRANSPORT ACCIDENTS IN BRAZIL}

\begin{abstract}
The present study aimed to analyze the trend in mortality by land transport accidents among Brazilian elderly individuals, from 1996 to 2013. Ecological, time-series study with secondary data collected by the Mortality Information System in April, 2015 concerning deaths by transport accidents. There were 88,273 deaths of elderly individuals caused by land transport accidents in Brazil, in the study period. All Brazilian regions showed a rising trend in mortality by transport accidents, which were more significant in the Northeastern region, followed by the Southern, Northern, Southeastern and Central-Western regions. These findings reveal the importance of surveillance of transport accidents, to support the implementation of effective health promotion policies, prevention and reduction of these events.
\end{abstract}

DESCRIPTORS: Traffic accidents; Mortality; Elderly; Time-series studies; Geriatric Nursing.

\section{TENDENCIA DE LA MORTALIDAD POR ACCIDENTES DE TRANSPORTE TERRESTRE DE ANCIANOS EN BRASIL}

RESUMEN: El objetivo fue analizar la tendencia de la mortalidad por accidentes de transporte terrestre en ancianos brasileños en el período de 1996 a 2013. Estudio ecológico de series temporales, con datos secundarios obtenidos a través del Sistema de Información sobre Mortalidad, en abril de 2015, referentes a los decesos por accidentes de transporte. Hubo 88.273 decesos por accidentes de transporte en el período estudiado entre ancianos brasileños. Todas las regiones mostraron creciente tendencia de mortalidad por accidentes de transporte, resultando que el Noreste mostraba tendencia mayor, seguido del Sur, Norte, Sudeste y Centro Oeste. Los resultados expresan la importancia de la vigilancia de accidentes de transporte en el apoyo a la implementación de políticas efectivas de promoción de salud, prevención y reducción de estos eventos.

DESCRIPTORES: Accidentes de Tránsito; Mortalidad; Anciano; Estudios de Series Temporales; Enfermería Geriátrica.

${ }^{1}$ Enfermeira. Doutoranda em Enfermagem na Universidade Estadual de Maringá. Maringá, PR, Brasil.

${ }^{2}$ Matemático. Doutor em Estatística. Docente da Universidade Estadual de Maringá. Maringá, PR, Brasil.

${ }^{3}$ Enfermeira. Doutora em Saúde Pública. Docente de Enfermagem da Universidade Estadual de Maringá. Maringá, PR, Brasil.

${ }^{4}$ Educador Físico. Doutor em Ciências Farmacêuticas. Docente de Enfermagem da Universidade Estadual do Paraná. Paranavaí, PR, Brasil.

${ }^{5}$ Enfermeira. Doutora em Enfermagem. Docente de Enfermagem da Universidade Estadual de Maringá. Maringá, PR, Brasil.

Autor Correspondente:

Recebido: 13/01/2017

Giovana Aparecida de Souza Scolari

Finalizado: 30/06/2017

Universidade Estadual de Maringá

Av. Colombo, 5790 - 87020-900 - Maringá, PR, Brasil

E-mail: giscolarigs@gmail.com 


\section{INTRODUÇÃO}

Em âmbito mundial, devido à melhoria nos cuidados à saúde, à diminuição da taxa de fecundidade e ao aumento da expectativa de vida ao nascer, ocorre o processo de envelhecimento estrutural da população, o qual tem se intensificado nas últimas décadas ${ }^{(1-2)}$. No Brasil, projeta-se para 2025 um contingente de 32 milhões de pessoas com 60 anos ou mais, o que fará do país o sexto em termos de população idosa ${ }^{(1)}$.

Os problemas de saúde e óbitos em idosos, frequentemente, são relacionados às doenças crônicodegenerativas, entretanto, os agravos por causas externas merecem destaque, devido ao aumento registrado nos últimos anos, sobretudo os acidentes de transporte, que são comuns e apresentam os maiores coeficientes ${ }^{(3)}$. O Acidente de Transporte Terrestre (ATT) é conceituado como episódio não intencional e evitável, capaz de gerar lesões físicas e emocionais, que envolvem pedestres, motocicletas e ocupantes de veículos ${ }^{(4)}$.

O envelhecimento, como processo natural, leva ao declínio das questões funcionais, tornando os indivíduos mais vulneráveis aos acidentes, sobretudo aos de transporte ${ }^{(2)}$. E por possuírem capacidade reduzida de recuperação de lesões, devido às doenças preexistentes, os idosos acabam evoluindo a óbito por lesões menos graves e de modo mais precoce do que os indivíduos mais novos. Tal afirmativa é corroborada pela literatura, devido aos coeficientes de mortalidade por causas externas apresentarem-se próximas aos de adolescentes e adultos jovens ${ }^{(5-6)}$.

Em 2013, houve no Brasil 151.683 óbitos da população em geral por causas externas e 27\% decorreram dos ATT. Esta proporção é similar quando se analisa os óbitos da população idosa no mesmo período, uma vez que estes representaram 26.933 do total de mortes por causas externas, das quais $24 \%$ foram relacionados a $\mathrm{ATT}^{(7)}$.

É oportuno destacar que existem políticas públicas direcionadas às pessoas vítimas de ATT, bem como voltadas às pessoas idosas. Porém, mesmo com as políticas que contemplam esta temática, tratase de uma problemática que deve ser ainda amplamente discutida pelas esferas governamentais, a fim de minimizar os riscos de acidentes e melhorar o atendimento de reabilitação para esta população(8) para que haja a redução destes acidentes.

Acerca da complexidade do envelhecimento ligada à gravidade que os ATT representam para a população idosa, julgou-se relevante investigar a ocorrência deste evento quando relacionado ao óbito, a fim de contribuir com as políticas públicas, e consequentemente proporcionar segurança no transporte destes indivíduos. Assim, o presente estudo teve como objetivo analisar a tendência da mortalidade por ATT em idosos brasileiros no período de 1996 a 2013.

\section{MÉTODO}

Realizou-se estudo ecológico, de séries temporais da mortalidade por acidentes de transporte entre idosos brasileiros, no período de 1996 a 2013.

O Brasil possui 5.570 municípios divididos em cinco regiões: Centro-Oeste, que é composta por quatro Estados, Nordeste por nove Estados, Norte tem sete Estados, Sudeste quatro Estados e a Sul três Estados, com população total estimada de 20.590 .599 de pessoas com 60 anos ou mais, o que representa $10,7 \%$ da população geral. A população idosa residente em cada uma das regiões no ano de 2010 foi de 6\% na Centro-Oeste, no Nordeste 26,4\%, na região Norte 5,2\%, na região Sudeste o número de idosos foi expressivo com $46,2 \%$ e $16 \%$ no Sul do país ${ }^{(1)}$.

Os dados foram coletados no mês de abril de 2015, no Sistema de Informação sobre Mortalidade (SIM) do site do Departamento de Informática do Sistema Único de Saúde (DATASUS), que fornece informações sobre óbitos, através do programa Tabnet, selecionando-se a variável "óbito por residência". A população do estudo consistiu em indivíduos com 60 anos ou mais de idade, que morreram devido a ATT, no Brasil, no período de 1996 a 2013.

A análise contemplou o período supracitado, pois1996 foi o ano em que o SIM passou a registrar as 
causas de óbito de acordo com as regras da décima revisão da Classificação Internacional de Doenças e Estatísticas Relacionadas com os Problemas de Saúde (CID-10). O último ano analisado foi 2013, uma vez que as informações do SIM estavam disponíveis até este período quando os dados foram coletados.

Os dados da população são referentes às informações dos recenseamentos de 2000 e 2010 e demais contagens populacionais e estimativas, obtidas no site do Ministério da Saúde ${ }^{(1)}$.

As causas de óbito estão classificadas segundo as regras da CID-10(9). Foram analisados os óbitos codificados como: Pedestre (V01 a V09), Ciclista (V10 a V19), Motociclista (V20 a V29), Ocupante de triciclo motorizado (V30 a V39), Ocupante de automóvel (V40 a V49), Ocupante de caminhonete (V50 a V59), Ocupante de veículo de transporte pesado (V60 a V69), Ocupante de ônibus (V70 a V79), Outros acidentes de transporte terrestre (V80 a V89) ${ }^{(9)}$.

Para verificar o comportamento e a tendência da mortalidade por acidentes de trânsito foi utilizada a regressão linear com estimativas dos parâmetros a partir do método de mínimos quadrados. $O$ modelo utilizado foi: $y_{i}=\beta_{0}+\beta_{1} X_{i}+\beta_{2} X i^{2}+\ldots+\beta_{p} X^{j}+e^{i}$, onde $y_{i}$ é o número de mortes por acidentes de transporte terrestre; $X_{i}$ é o ano, o qual variou de 1996 a 2013; $i$ é o número de observações, isto é, $i=1, \ldots, 18$. e $j$ determina o grau máximo no polinômio e $p$ determina a quantidade de parâmetros do modelo(10).

O primeiro modelo testado foi o de regressão linear simples $\left(Y=\beta_{0}+\beta_{1} X\right)$ e quando necessário foram testados os modelos de segundo grau $\left(Y=\beta_{0}+\beta_{1} X+\beta_{2} X^{2}\right)$ e terceiro grau $\left(Y=\beta_{0}+\beta_{1} X+\beta_{2} X^{2}+\beta_{3} X^{3}\right)$. Obteve-se o melhor modelo de regressão selecionado pelo critério de Akaike ${ }^{(11)}$.

Para verificar o comportamento médio e possível tendência, foi ajustado um modelo linear de grau um. Em um modelo polinomial de grau um, o parâmetro $\beta_{1}$ é considerado o coeficiente angular do modelo. Para verificar se o crescimento de todas as regiões possuía um mesmo coeficiente angular, foram construídos intervalos de confiança a 95\% para o parâmetro $\beta_{1}{ }^{(10)}$.

Considerando que a pesquisa utilizou dados secundários de bases oficiais, sendo, portanto de domínio público, e pelo fato de haver sigilo acerca das informações de identificação inerentes aos seres humanos envolvidos, este estudo dispensou a apreciação e a aprovação por Comitê de Ética em Pesquisa.

\section{- RESULTADOS}

No período de 1996 a 2013, ocorreram 325.716 óbitos por causas externas entre idosos brasileiros e destas, $27 \%(n=88.273)$ foram codificados como ATT. Dos óbitos por ATT ( $n=88.273$ ), 5,5\% foram na Região Norte, 43,2\% na região Sudeste, 19,6\% na região Sul, 9,3\% na Região Centro-Oeste e 22,2\% na região Nordeste.

A região Nordeste, em especial, apresentou uma tendência de crescimento maior do que as demais (Figura 1). 


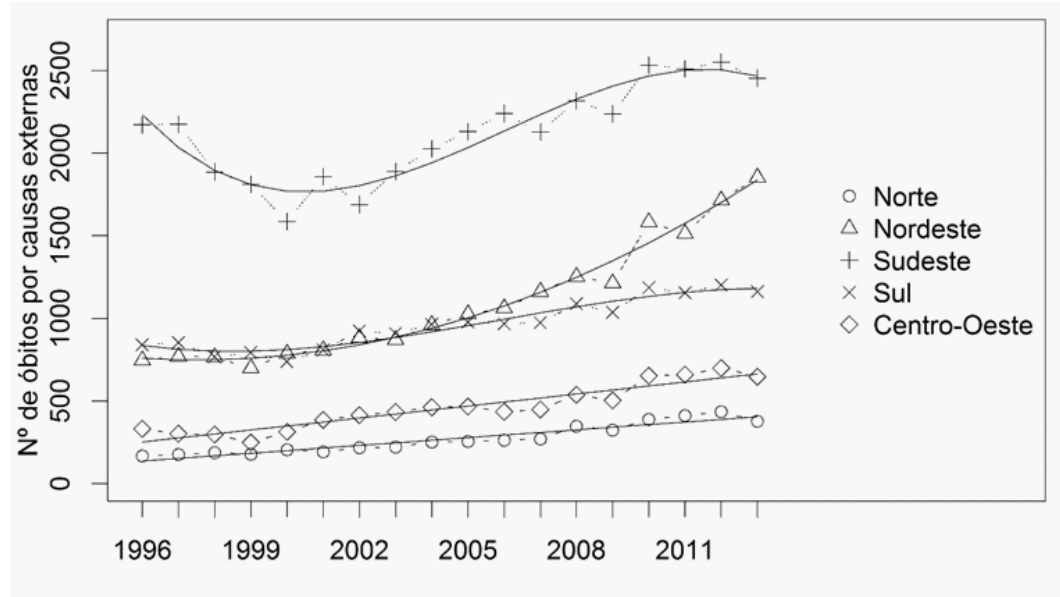

Figura 1 - Tendência de mortalidade por acidentes de transporte terrestre entre idosos brasileiros no período de 1996 a 2013. Maringá, PR, Brasil, 2015

Fonte: SIM/SUS, 2015.

Os resultados da análise de tendência da mortalidade, assim como os modelos ajustados para cada região são apresentados na Tabela 1. Todos os modelos apresentaram resíduos que podem ser considerados normais pelo teste de Shapiro-Wilk a 95\% de confiança.

Tabela 1 - Tendência da mortalidade por acidentes de transporte terrestre entre idosos no período de 1996 a 2013, de acordo com as regiões do Brasil. Maringá, PR, Brasil, 2015

\begin{tabular}{|c|c|c|c|c|}
\hline Região & Modelo & Tendência & $\mathbf{R}^{2 *}$ & Valor-p** \\
\hline Norte & $y=15,74 x+120,91$ & 1996-2013: Crescente & 0,9 & 0,15 \\
\hline Nordeste & $y=4,52 x^{2}-22,64 x+776,66$ & 1996-2013: Crescente & 0,97 & 0,15 \\
\hline Sudeste & $y=-1,09 x^{3}+36,12 x^{2}-298,04 x+2492,59$ & $\begin{array}{l}\text { 1996-2000: Decrescente } \\
\text { 2000-2011: Crescente } \\
\text { 2011-2013: Decrescente }\end{array}$ & 0,89 & 0,35 \\
\hline Sul & $y=-0,23 x^{3}+7,76 x^{2}-45,77 x+874,74$ & $\begin{array}{l}\text { 1996-1999: Decrescente } \\
\text { 1999-2013: Crescente }\end{array}$ & 0,92 & 0,76 \\
\hline $\begin{array}{l}\text { Centro- } \\
\text { Oeste }\end{array}$ & $y=24,18 x+227,66$ & 1996-2013: Crescente & 0,88 & 0,47 \\
\hline
\end{tabular}

*Coeficiente de determinação; ${ }^{* *}$ Os resíduos podem ser considerados normais pelo teste de Shapiro-Wilk a 5\% de significância.

Fonte: SIM/SUS, 2015.

A região Sudeste apresentou tendência decrescente da mortalidade nos anos de 1996 a 2000 e 2011 a 2013 e a Sul entre 1996 a 1999, nas demais regiões e em todos os outros períodos houve tendência de crescimento de óbitos por ATT entre os idosos brasileiros, no período de 1996 a 2013 (Tabela 1).

A região Nordeste apresentou maior valor de $\beta_{1}$ e, sobrepôs à região Sudeste. $O$ valor de $\beta_{1}$ em um modelo linear simples pode ser interpretado como a taxa de crescimento. Ou seja, quando há sobreposição dos intervalos, não se pode afirmar que as regiões são diferentes. Todavia, quando os intervalos não se sobrepõem, deve-se afirmar que uma região difere da outra. Logo, pode ser afirmado que a região Nordeste apresentou a maior tendência de crescimento e que esta diferiu de todas as demais (Figura 2). Ou seja, é possível verificar que houve sobreposição dos intervalos de confiança das regiões Norte, Sul, Sudeste e Centro-Oeste, de modo que a tendência de crescimento dessas regiões pode ser considerada igual. 


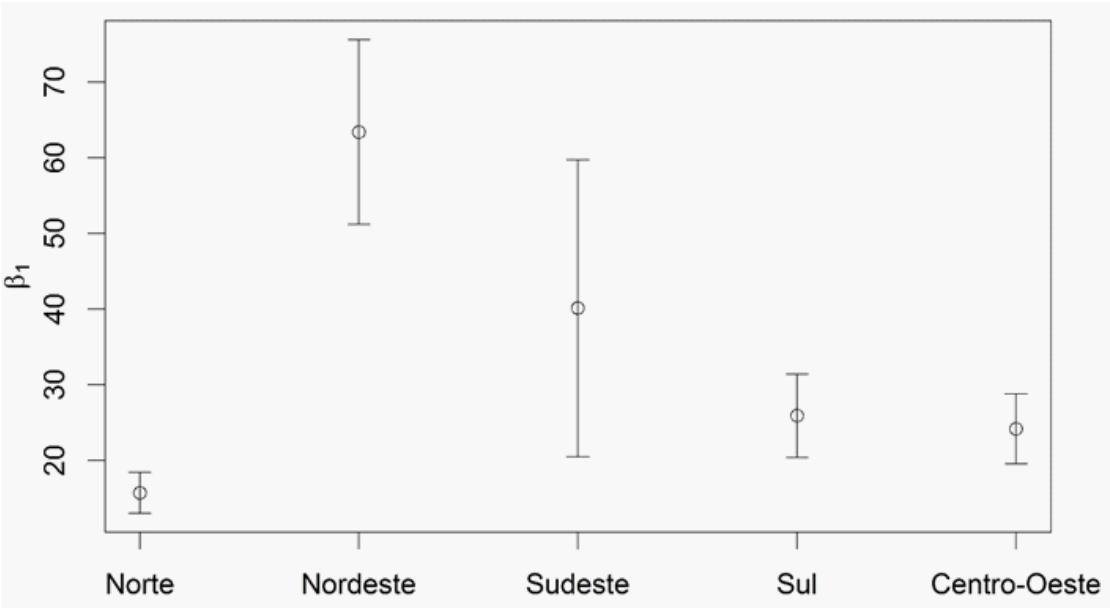

Figura 2 - Intervalos de confiança para o modelo $\beta_{1}$, de acordo com as regiões do Brasil, 1996 a 2013. Maringá, PR, Brasil, 2015

Fonte: SIM/SUS, 2015.

Houve ajuste de um modelo polinomial para cada região e respectivos tipos de acidente, a Figura 3 apresenta em síntese estes resultados.

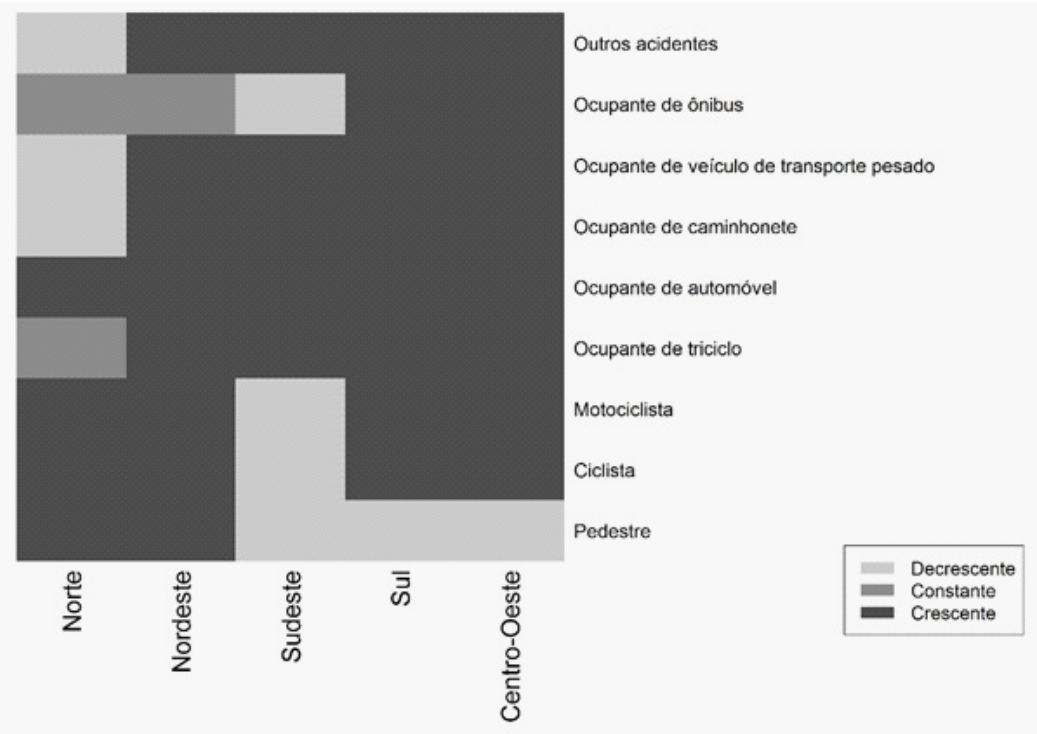

Figura 3 - Tendência de mortalidade pelos tipos de acidentes de transporte terrestre entre idosos brasileiros no período de 1996 a 2013. Maringá, PR, Brasil, 2015

Fonte: SIM/SUS, 2015.

Nota-se, a partir da análise de tendência da região Norte, que os acidentes envolvendo idosos pedestres, ciclistas, motociclistas e ocupantes de automóvel tiveram tendência crescente, já ocupantes de caminhonetes e de veículos de transportes pesado e outros acidentes de transporte apresentaram tendência decrescente, enquanto ocupantes de triciclo tiveram a tendência constante entre 1996 a 2013.

Na região Nordeste, a tendência de crescimento foi para todos os acidentes envolvendo idosos, com exceção do subtipo ocupante de ônibus que teve uma tendência constante.

Referente à análise do Sudeste, a tendência crescente esteve para ocupantes de triciclo, de automóvel, de caminhonete e de transporte de veículo pesado e para outros tipos de acidentes de 
transporte, o restante dos tipos de acidentes entre idosos decresceram. Constata-se que as regiões Sul e Centro-Oeste apresentaram tendências de mortalidade crescente para todas as categorias no período estudado, com exceção do subtipo pedestres que decresceram.

\section{DISCUSSÃO}

Nos 18 anos do estudo, mesmo com a oscilação da tendência em determinados períodos, constata-se tendência crescente para o número de óbitos em idosos relacionados aos ATT. Vários fatores precisam ser considerados na análise da variação da tendência, com destaque ao aumento populacional no país desta faixa etária, melhora das condições econômicas e também a melhora na qualidade das informações registradas na Declaração de Óbito (DO).

No que se refere à DO, sabe-se que os óbitos por causas básicas eram registrados em "outras causas externas" ou "acidentes de natureza não especificada", ou até por "outros acidentes de transporte", agora estariam sendo melhores definidos no preenchimento. Contudo, os registros da DO ainda necessitam ser aperfeiçoados.

A análise de tendência de mortalidade permite avaliar não somente o comportamento dos ATT em uma determinada população, mas também de forma indireta as ações preventivas, como o aperfeiçoamento da vigilância dos ATT, a efetivação das políticas públicas relacionadas à temática. E ainda, a boa articulação entre o atendimento pré-hospitalar e a resposta ágil e qualificada da assistência hospitalar de urgência e sua retaguarda, e se as ações de controle tanto em âmbito primário quanto secundário estão sendo úteis para a redução desses acidentes.

Pela análise de um modelo linear simples, pode-se observar que a região Nordeste foi a que se sobressaiu, apresentando a maior tendência de crescimento, enquanto as demais tiveram tendência similar. Tal fato corrobora com a literatura, em que se observam mudanças nesta região, devido ao aumento dos números dos aglomerados e consequente elevação nas taxas de mortalidade ${ }^{(12)}$.

Além destes fatores, a cultura nordestina retrata resistência ao uso de equipamentos de segurança, principalmente o cinto de segurança nos bancos dianteiro e traseiro. Sabe-se que o uso deste dispositivo é uma medida eficaz na redução de lesões graves em consequência dos eventos de trânsito, porém o seu baixo uso requer o desenvolvimento indispensável de estratégias de educação da população e intensificação da fiscalização ${ }^{(12)}$.

Observa-se que a região Sudeste apresentou os maiores valores de acidentes de transporte, o que se assemelha a outro estudo em um município desta região, que se destacou com 35,6\% do risco de morte para esta causa ${ }^{(12)}$. Entretanto, averígua-se decrescente tendência entre os anos de 1996 a 2000 e 2011 a 2013, o que pode ter sido influenciada pela especificidade no preenchimento da DO como mencionado anteriormente, e ainda após 2008, pela implantação da Lei Seca ${ }^{(13)}$.

A promulgação da Lei 11.705/2008, popularmente conhecida como "Lei Seca", foi uma das iniciativas das autoridades na tentativa de reduzir os ATT, quando se estabeleceu normas legais para punir os transgressores. A Lei provocou alterações de atitudes na população no que diz respeito ao consumo de bebidas alcoólicas e à condução de veículos automotores. O Ministério da Saúde relatou redução dos atendimentos em vias públicas em todo o país, o que gerou uma economia de 50 milhões de reais, apenas no primeiro mês após aprovação desta lei ${ }^{(14)}$.

Embora a região Norte tenha exibido a menor tendência de crescimento, constatou-se em uma pesquisa que os envolvidos em ATT nesta região foram os que mais deixaram de cumprir as regras de segurança no trânsito, quando comparado com as demais regiões do país ${ }^{(12)}$.

Estas diferenças regionais já são observadas desde a implantação do Código Nacional de Trânsito, em 1998, com redução considerável nas taxas de mortalidade por ATT no Brasil, nas regiões Sul e Sudeste, e ausência do mesmo efeito nas regiões Nordeste, Norte e Centro-Oeste ${ }^{(13)}$.

Em países da África, Ásia e América Latina, grande parte das mortes por ATT são de pedestres e ciclistas. Os mais acometidos pertencem ao grupo de baixa renda ${ }^{(12)}$. No presente estudo, as regiões Norte e Nordeste tiveram tendência de crescimento para o subtipo pedestre, enquanto que para 
ciclistas foram ambas as regiões, além da região Sul.

Idosos são suscetíveis aos atropelamentos devido à diminuição do senso percepção e da mobilidade ${ }^{(12,15)}$. Estudo brasileiro demonstrou que atropelamento e morte aumentam em idosos mais velhos $^{(16)}$, o que corrobora com pesquisa desenvolvida nos Estados Unidos em que indivíduos que tinham idade igual ou superior a 80 anos representavam 39\% dos idosos atropelados ${ }^{(5)}$.

Estima-se que ocorram anualmente 1,2 milhão de mortes e mais de 50 milhões de feridos em decorrência das eventualidades no trânsito, sendo a maior parte entre usuários da rede viária, pedestres, ciclistas e motociclistas ${ }^{(3)}$. Nesta pesquisa, apenas a região Sudeste apresentou tendência decrescente para a mortalidade de acidentes envolvendo motociclistas, enquanto o oposto ocorreu para as demais regiões no período em estudo.

É alarmante o número de óbitos por eventos envolvendo motocicletas. Entre 1996 e 2007 houve crescimento de $820 \%$ de acidentes e um dos fatores que pode ter contribuído é a expansão na frota de motocicletas no país e a rapidez e baixo custo destes ${ }^{(17)}$. Os acidentes com motocicletas apresentam potenciais acidentes com óbito ${ }^{(18)}$.

Neste estudo, constatou-se que em todas as regiões houve tendência de crescimento para algum dos subtipos dos ocupantes de veículos, seja de triciclo motorizado, automóvel, caminhonete, veículo de transporte pesado ou ônibus. Estudo realizado com o objetivo de analisar a tendência temporal da mortalidade por ATT entre 2000 a 2010 verificou aumento de óbitos para ocupantes destes veículos em Estados das regiões Sudeste, Sul, Nordeste e Centro-Oeste ${ }^{(13)}$.

Outra pesquisa realizada na região Nordeste encontrou alto percentual de mortes por ocupantes de veículo, que representa o principal meio com vítimas fatais. Isso pode ser justificado devido à falta de conscientização sobre a necessidade do uso de dispositivos de segurança, como cinto de segurança, "airbags", cintos de segurança para crianças e capacetes para motociclistas ${ }^{(17)}$.

Ressalta-se que o desenvolvimento econômico pode ter influenciado no aumento do número de óbitos por ATT, devido à grande circulação de elevado número de veículos a motor sem regular o estabelecimento de mecanismos de adaptação a esse crescimento. Vale destacar a escassa fiscalização, a precariedade de transporte público e a infraestrutura imprópria como fatores juntamente implicados na violência urbana ${ }^{(19)}$.

Os ATT são, na maioria das vezes, previsíveis e passíveis de prevenção. Estabelece, portanto, problema suscetível à análise racional e intervenções. A análise da situação de saúde pode auxiliar no planejamento das ações e enfrentamento da questão. Assim, sabe-se que a prevenção de acidentes é um tema de saúde pública, principalmente na população idosa, que tem suas particularidades, cujas ações devem considerar a vinculação entre vários setores.

Iniciativas no Brasil para enfrentar a alta taxa de mortalidade no trânsito vem sendo implementadas de forma mais decisiva a partir de 1998 com a efetivação do Código Nacional de Trânsito, que proporcionou, no primeiro ano de implantação, redução de $7,4 \%$ na taxa de mortalidade ${ }^{(14)}$ por acidentes de trânsito.

Além disso, o Ministério da Saúde tem liderado as ações de vigilância e prevenção de lesões e mortes provocadas pelo transporte e de promoção da saúde, dentre as quais se destaca a Política Nacional de Redução da Morbimortalidade por Acidentes e Violências (PNRMAV), sancionada pela Portaria GM/MS n ${ }^{\circ}$ 737, de 16/05/2001. Entretanto, observa-se até a contemporaneidade que não há qualquer avaliação da efetividade destas leis, baseando-se na redução das taxas de mortalidade e morbidade por ATT. Somado a tal fato, os resultados desta pesquisa vão de encontro com a literatura, referente à não redução dos ATT após a implantação destas leis, ou seja, ocorreram algumas mudanças, porém apresentam raros resultados ${ }^{(15)}$.

As intervenções relacionadas ao envelhecimento devem ter a finalidade de garantir que a capacidade funcional, física e mental sejam mantidas com qualidade. É imprescindível que além da acessibilidade aos serviços, haja a flexibilidade para identificar situações que estão em constante mudança, buscando atender aos idosos de maneira integral, com provisão de serviços sociais, condições de trabalho, de moradia, seguridade, alimentação, transporte e recreação.

Faz-se necessária a construção de área urbana mais adequada às pessoas idosas, bem como o 
investimento na cultura da solidariedade, almejando uma sociedade para todos. Deslocar-se com segurança é um direito essencial, e algumas medidas precisam ser debatidas, como semáforos apropriados, principalmente nas vias de maior movimento, pontos de ônibus protegidos, informações acessíveis e legíveis, ponderando as limitações visuais advindas do envelhecimento ${ }^{(20)}$. Ainda, fiscalização mais rígida no trânsito, adoção de medidas educativas e punitivas no combate a esses acidentes e proteção dos usuários vulneráveis das vias públicas ${ }^{(17)}$.

As limitações do presente estudo deram-se pelo método estatístico adotado, pois existem percalços quanto ao emprego de regressão polinomial, que não controla a auto correlação serial, bem como entraves a respeito da utilização de dados secundários sobre a qualidade das informações referente aos óbitos, que podem diferir de acordo com a organização dos serviços em cada Estado/região. Contudo, tais limitações não invalidam o esforço nas análises desses dados e a contribuição desse estudo para o conhecimento da situação de saúde da população idosa e do melhoramento dos dados sobre a causa básica da morte.

\section{- CONCLUSÃO}

Os resultados deste estudo proporcionaram reflexões sobre o perfil da mortalidade por acidentes de transporte entre idosos brasileiros, no período de 1996 a 2013. Mostram importante crescimento da tendência em todas as regiões, com destaque ao Nordeste, e para os tipos de acidentes evidenciou-se tendência de crescimento, em todas as regiões, no período investigado para os ocupantes de veículos.

Sugere-se que haja formulação de estratégias consistentes de segurança rodoviária, apoiados por políticas, planos e programas nacionais que estabeleçam intervenções específicas, como melhoramento da infraestrutura viária e adequação e/ou melhoria das instituições de saúde ao atendimento das vítimas de trauma. Além disso, recomenda-se o estímulo de práticas educativas abordando sobre os riscos de ATT para população em geral e para idosos. Por fim, novos estudos são necessários, especialmente para avaliação e suporte das políticas, planos e programas que visam à redução da morbimortalidade por ATT e também das que forem posteriormente implantadas.

\section{REFERÊNCIAS}

1. Ministério do Planejamento (MP). Instituto Brasileiro de Geografia e Estatística (IBGE). Censos Demográfico de 2010[Internet] 2011[acesso em 14 jul 2015]. Disponível: http://www.ibge.gov.br.

2. Souza AS, Andrade CC, Reis Junior AP, Meira EC, Menezes MR, Gonçalves LHT. Atendimento ao idoso hospitalizado: percepções de profissionais de saúde. Cienc Cuid Saúde. [Internet] 2013;12(2) [acesso em 28 jul 2015]. Disponível: http://dx.doi.org/10.4025/cienccuidsaude.v12i2.18999.

3. Lima RHS, Amorim RT, Martins VA, Rodrigues LS, Batista RFL. Mortalidade por causas externas no estado do Maranhão, Brasil: tendências de 2001 a 2010. Rev Pesq Saúde.[Internet] 2013;14(2) [acesso em 15 jul 2015$].$ Disponível: http://www.periodicoseletronicos.ufma.br/index.php/revistahuufma/article/view/2301/4064.

4. d'Avila S, Campos AC, Cavalcante GMS, Silva CJP, da Nóbrega LM, Ferreira EF. Characterization of victims of aggression and transportation accidents treated at the Forensic Medicine and Dentistry Institute - Campina Grande, Paraíba, Brazil - 2010. Ciênc.saúde coletiva. [Internet] 2015;20(3) [acesso em 16 jul 2015]. Disponível: http://dx.doi.org/10.1590/1413-81232015203.12922014.

5. Mcelroy LM, Juern JJ, Bertleson A, Xiang Q, Szabo A, Weigelt J. A single urban center experience with adult pedestrians struck by motor vehicles. WMJ. [Internet] 2013;112(3)[acesso em 21 jul 2015]. Disponível: https:// www.ncbi.nlm.nih.gov/pmc/articles/PMC3845352/pdf/nihms519491.pdf.

6. Rodrigues], Ciosak SI. Idosos vítimas de trauma: análise de fatores de risco. Rev.esc. enferm. USP.[Internet] 2012;46(6)[acesso em 22 jul 2015]. Disponível: http://dx.doi.org/10.1590/S0080-62342012000600017.

7. Ministério da Saúde (BR). Sistema de Informações sobre Mortalidade (SIM/SUS). [Internet] 2014[acesso em 10 abr 2015]. Disponível:http://www2.datasus.gov.br/DATASUS/index.php?area=0205. 
8. Ministério da Saúde (BR). Secretaria de Atenção a Saúde. Departamento de Atenção Básica. Envelhecimento e saúde da pessoa idosa. Brasília (DF): Ministério da Saúde; 2006.

9. Organização Mundial da Saúde (OMS). ClassificaçãoEstatística Internacional de Doenças e Problemasrelacionados à Saúde. 10ª Revisão. São Paulo: Editorada Universidade de São Paulo; 1994.

10. Rencher AC, Schaalje GB. Linear models in statistics. $2^{a}$ ed. John Wiley \& Sons, Hoboken: NJ; 2008.

11. Akaike H. A new look at the statistical model identification. IEEE Transactions on Automatic Control.[Internet] 1974;19(6) [acesso em 02 ago 2015].Disponível: http://dx.doi.org/10.1109/TAC.1974.1100705.

12. Malta DC, Mascarenhas MDM, Bernal RTI, da Silva MMA, Pereira CA, Minayo MCS,et al. Análise das ocorrências das lesões no trânsito e fatores relacionados segundo resultados da Pesquisa Nacional por Amostra de Domicílios (PNAD) Brasil, 2008. Ciênc.saúde coletiva. [Internet] 2011;16(9) [acesso em 29 jul 2015]. Disponível: http://dx.doi.org/10.1590/S1413-81232011001000005.

13. de Morais Neto OL, Montenegro MMS, Monteiro RA, Siqueira Júnior JB, da Silva MMA, de Lima CM,et al. Mortalidade por acidentes de transporte terrestre no Brasil na última década: tendência e aglomerados de risco. Ciênc. saúde coletiva. [Internet] 2012;17(9) [acesso em 30 jul 2015]. Disponível: http://dx.doi.org/10.1590/S141381232012000900002.

14. Abreu AMM, Jomar RT, Thomaz RGF, Guimarães RM, de Lima JMB, Figueirò RFS. Impacto da Lei Seca na Mortalidade por acidentes de trânsito. Rev Enferm UERJ.[Internet] 2012;20(1) [acesso em 03 ago 2015]. Disponível: http://www.e-publicacoes.uerj.br/index.php/enfermagemuerj/article/view/3970.

15. Bacchieri G, Barros AJD. Acidentes de trânsito no Brasil de 1998 a 2010: muitas mudanças e poucos resultados. Rev. Saúde Pública.[Internet] 2011;45(5) [acesso em 18 jul 2015].Disponível: http://dx.doi.org/10.1590/S003489102011005000069.

16. Chandran A, Sousa TRV, Guo Y, Bishai D, Pechansky F, Vida No Transito Evaluation Team. Road traffic deaths in Brazil: rising trends in pedestrian and motorcycle occupant deaths. Traffic Inj Prev.[Internet] 2012;13(Suppl 1) [acesso em 03 ago 2015]. Disponível: https://dx.doi.org/ 10.1080/15389588.2011.633289.

17. Reichenheim ME, de Souza ER, Moraes CL, Jorge MHPM, da Silva CMFP, Minayo MCS. Violence and injuries in Brazil: the effect, progress made, and challenges ahead. Lancet.[Internet] 2011;377(9781) [acesso em 02 jul 2015]. Disponível: http://dx.doi.org/10.1016/S0140-6736(11)60053-6.

18. de Almeida RLF, Bezerra Filho JG, Braga JU, Magalhaes FB, Macedo MCM, Silva KA. Man, road and vehicle: risk factors associated with the severity of traffic accidents. Rev. Saúde Pública. [Internet] 2013;47(4) [acesso em 05 jul 2015]. Disponível: http://dx.doi.org/10.1590/S0034-8910.2013047003657.

19. de Lima MVN, de Oliveira RZ, de Lima RB, de Oliveira LZ, de Lima AP Fujii, FN. Óbitos por acidentes de transporte terrestre em município do noroeste do Paraná - Brasil. Rev BrasMedFam Comunidade. [Internet] 2014;9(33) [acesso em 05 jul 2015]. Disponível: http://dx.doi.org/10.5712/rbmfc9(33)854.

20. dos Santos AMR, Rodrigues RAP, Diniz MA. Trauma no idoso por acidente de trânsito: revisão integrativa. Rev.esc. enferm. USP. [Internet] 2015;49(1)[acesso em 05 jul 2015]. Disponível: http://dx.doi.org/10.1590/S0080623420150000100021. 